$9(1)(2020) 24-28$
Indonesian Journal of Early Childhood
Education Studies

\title{
How is Piaget's Theory Used to Test The Cognitive Readiness of Early Childhood in School?
}

\author{
Abdul Kholiq \\ DOI: http://dx.doi.org/10.15294/ijeces.v9i1.37675
}

Universitas Pendidikan Indonesia, Indonesia

\section{History Article \\ Submitted 20 February 2020 Revised 13 May 2020 Accepted 4 June 2020 \\ Keywords \\ Cognitive; Early Childhood; Piaget}

\begin{abstract}
This study aims to examine Piaget's cognitive theory of early childhood readiness to enter elementary school. The method used is quantitative descriptive, using samples of early childhood selected based on the criteria of 5 years of age. The results of the study were processed using statistical calculations. The results obtained were that the instruments developed were effective enough to test cognitive readiness of early childhood in elementary school entrance examinations. In addition, the average tested child has a fairly good readiness but requires guidance by the teacher so that his cognitive abilities develop optimally.
\end{abstract}

\section{How to Cite}

Kholiq, A. (2020). How is Piaget's Theory Used to Test The Cognitive Readiness of Early Childhood in School?. Indonesian Journal of Early Childhood Education Studies, 9(1), 24-28.
Correspondence Author:

E-mail: abdulkholiq@upi.edu
p-ISSN 2252-8415

e-ISSN 2476-9584 


\section{INTRODUCTION}

The theory of child development based on developmental aspects is increasingly being deepened by scientists. Diverse child development is then categorized into several aspects including the psychomotor, language, cognitive, social, and emotional aspects (Devi, 1998; Madaschi et al, 2016). The age stages of child development are also increasingly known, such as age before school and school age. Age stages in the development of the child can be different between one child and another (Institute of Medicine NRC, 2015). This is influenced by factors that are divided into internal and external factors (Unsworth, 2011; Rintoul, et al, 1998; Spies, et al, 2017; Molai, 2016).

Internal factors such as genetics or innate and external factors such as nutritional intake in food, the environment, culture, lifestyle, etc. (Pem, 2015). Unity between the factors of heredity, environment, and maturity of individuals in meeting environmental needs is then referred to as mental age. The mental age of each individual is certainly unique so even though there is a general classification, it is necessary to analyze in depth the uniqueness of each individual (Adeler \& Fagley, 2009).

The leaders in classifying the stages of a child's development differ based on his typical approach, as well as his perspective on children. In this report the author will analyze and examine the development of children in Piaget's cognitive view. The aspects studied were about theoretical concepts, stages of development, development of instruments to test the readiness of children to enter elementary school, and analysis of the results of the trial of these instruments.

In cognitive development in childhood, Piaget revealed that children play an active role in gaining knowledge. Unlike behavior where children passively wait for information or stimulus (Parke \& Gauvain, 2009). In addition, when children get new information, they actively try to adjust to the experience or knowledge they have acquired before. In other words, children reconstruct their own understanding. Thus, the theory developed by Piaget refers to constructivist views (Bada, 2015).

In the development of children understanding information or thought processes, the main key to intellectual development is the organizational process and adaptation to the scheme that is obtained by children (Eccles, 1999). Schemes are units of information grouped in an individual's mental understanding, schemes are formed based on the understanding and interaction of individuals with their environment, in other words schemes will adapt to their environment and change during individual cognitive development (Bormanaki \& Khoshhal, 2017). Organization is an individual mental process to regulate or construct personal understanding that involves the process of adaptation to newly acquired information (Parke \& Gauvain, 2009). Adaptation to the environment is done through two processes, namely the assimilation process and accommodation.

In the child adaptation process, understanding the world, the information obtained will be assimilated and accommodated. Assimilation is a cognitive process in which a person integrates new perceptions, concepts or experiences into a scheme or pattern that is already in his mind (Lumen Learning). Assimilation is seen as a cognitive process that places and classifies new events or stimuli in existing schemes. This assimilation process continues, organizing and adapting itself to the environment in accordance with the new understanding that continues to evolve (Lefudin, 2017). Accommodation is the process of integrating new stimulus into a scheme that has been formed indirectly. The behavior that can be carried out individually is the process of modifying the scheme (Feldman, 2004). The process shows his ability to change his knowledge (accommodation) (Santrock, 2007). Next will be examined the stages of human cognitive development according to Piaget.

First, the sensorimotor stage runs from birth to around the age of two years (Wood, 2001). In this stage, the baby forms an understanding of the world by coordinating sensory experiences such as seeing and hearing with physical, motoric actions. At the beginning of this stage, newborns only have a reflex behavior pattern. At the end of the sensorimotor stage, two-year-old children are able to produce complex sensorimotor patterns and use primitive symbols (Marocco \& Belpaerme, 2010).

Second, preoperational stages that take place at 2-7 years are indicated by those who begin to represent their world with words, shadows and images. During this stage children start using language; their memory and imagination are also developing. At this stage children trust and express the relationship between the past and the future. Symbolic thoughts go beyond simple connections of sensory information and physical action (Simatwa, 2010).

There is a symbolic phase at the age of 2-4 years. At this stage, the child gains the ability to represent objects that are not seen mentally 
(Bashrin, 2015). This ability extends the mental world of children as indicated by the ability to randomly describe people, homes, cars, clouds, etc. In addition, there is a phase of Intuitive thinking (4-7 years), when children begin to practice primitive reasoning and want to know the answers to various questions. According to Piaget, during this stage the mode of intuitive thinking applies is characterized by free, fantasy and unique associations that sometimes make no sense (Simatwa, 2010).

Third, concrete operational stages between 7-12 years. At this stage, the child is able to perform operative actions, and logical reasoning replaces intuitive reason as long as the reasoning can be applied to specific and concrete examples (Moshman, 1998). Fourth, formal operational stages that begin around the age of 12 years. At this stage, the child moves through concrete experiences and thinking in abstract and more logical ways (McLeod, 2018). As part of their ability to think abstractly, they develop images of ideal situations. Santrock demonstrates an example when teenagers can see concrete elements $\mathrm{A}, \mathrm{B}$, and C in order to be able to make a logical conclusion that if $\mathrm{A}=\mathrm{B}$, and $\mathrm{B}=\mathrm{C}$, then $\mathrm{A}=\mathrm{C}$ (Santrock, 2007).

Based on the preliminary discussion and study of the literature, this scientific work was written to clarify Piaget's theory whether or not it can be applied in real life. Research will be conducted by developing a theory initiated by Piaget and then compiling research variables until the questions and research statements are obtained. Therefore, the purpose of this scientific work is to examine what Piaget's cognitive theory applies to the readiness of early childhood at a certain age in their thinking abilities.

\section{METHOD}

Research that has been done using a quantitative approach. The research design is descriptive which describes a single variable in the form of cognitive conditions of early childhood. The research sample is an early childhood chosen according to the criteria of 5 years old, amounting to 5 children. The method of data collection uses a list of questions that are tested on the sample then the data is processed using statistical rules.

\section{RESULT AND DISCUSSION}

Instruments to identify the readiness of children to enter primary school based on the stages of Piaget's development based on the stages of
Piaget's cognitive development, namely children entering primary school are in the preoperational stage 2-7 years (Joubish \& Muhammad, 2011). In general, children enter elementary school aged 6 or 7 years. Preoperational stages that take place at the age of 2-7 years are indicated by children who begin to represent their world with words, shadows, and images (Marwaha \& Binny, 2017). Symbolic thoughts go beyond simple connections of sensory information and physical action.

The following are the results of the trials of instruments that have been developed. Respondents' answers are transformed into Can/Cannot or True/False forms. Based on the answers of the five respondents, the scores of each item varied with a maximum score range of 5 and a minimum of 0 . The items answered correctly were all (score 5) by all respondents were numbers 2, 4, 5, 6 for symbolic aspects; then number $8,9,10,11$, $12,13,14,15$ for the intuitive aspects; then numbers 16, 18, 19, 20 for aspects of assimilation and number 25 for aspects of accommodation. The 17 numbers can be classified easily because all respondents can answer. Then what is answered (correct 3 or 4 ) by all respondents is number 1, 3 for symbolic aspects and number 17 for aspects of assimilation. The 3 numbers are classified as medium. The next answer (correct 1 or 2 ) is number 7 for symbolic aspects and number 22, 23, 24 for the accommodation aspect. The 4 numbers are quite difficult. Then the problem with a score of 0 is number 21 for the accommodation aspect. One number is a very difficult number because no respondent is able to answer correctly. It is known that this instrument has an easy composition of $68 \%$, moderate questions as much as $12 \%$, difficult questions as much as $16 \%$ and very difficult questions as much as $4 \%$. While the average ability of respondents in answering was $82.4 \%$. Therefore, there is still a difference of around $14 \%$ between the number of easy questions with the ability of respondents who mean respondents are not only able to do easy questions. According to the data, the percentage of the difficulty level of the question can be seen in the Figure 1 .

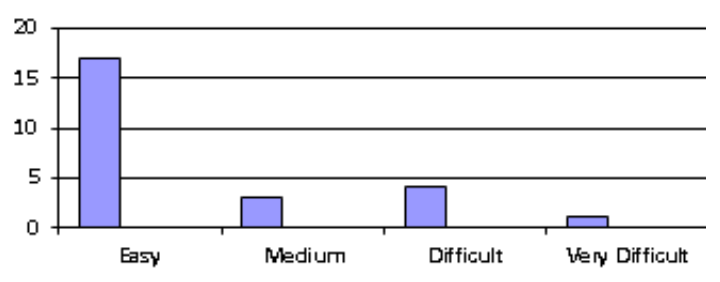

Figure 1. The level of difficulty of the question

Then the following is an analysis based on 
variable components. The intuitive aspect is the aspect that most children have. Children are able to reason primitive very well. Children today are easy to develop their knowledge and answer their curiosity. This can be analyzed because nowadays information access is so extensive, children can access knowledge through increasingly sophisticated technology and media. Next, the ability of children to be assimilated is still very good, $92 \%$ of them are kindergarten children who are able to integrate experience into existing schemes. The child is able to understand what he is facing or experience based on his knowledge. Then the symbolic aspects of respondents who are classified as good with the ability to recognize symbols in the form of images, colors, and words as a whole is $82.85 \%$. Then the least score is the ability of children to do accommodation, which results in $44 \%$. Children have not been able to integrate experience into the new scheme properly. The dominance of children's thinking is still assimilation. The possibility of a new child growing up and being able to do accommodation at a higher age between 6-7 years.

Overall the average ability to answer by the 1st to 5 th respondents was $79.76 \%$. These results indicate a good level of respondents' ability (in $1-100 \% 79.76 \%=$ good). Respondent 1 has the ability of $74.3 \%$ and is the smallest score compared to the ability of the other respondents. However, when looking at the indicators, respondents 1 as a whole graduate (the minimum limit is $60 \%$ ) on the intuitive and assimilation aspects, the other two are still below $60 \%$. Then respondent 2 has the same average score with respondent 3 which is $81.5 \%$. Respondents 2 are both symbolic, intuitive, and assimilating while respondent 3 is good in all aspects, namely symbolic, intuitive, assimilation, and accommodation. Then respondents $4 \mathrm{had}$ an average of $76.5 \%$ in both symbolic, intuitive and assimilation aspects. Similar to other respondents, the ability in the aspect of accommodation is classified as very low at $20 \%$. Then respondent 5 is the highest ability in the symbolic and intuitive aspects of $100 \%$ and the ability of the assimilation and accommodation aspects is $80 \%$ and $60 \%$. Then the average score of respondents 5 is $85 \%$, which is the best compared to other respondents. The influential factor is the age of the most likely influence, because the age of the respondents 5 is 5 years 10 months and the other respondents below it.

\section{Analysis of Instruments}

The instruments used in this trial have several analysis notes including the following: 1 . The instrument has not been tested for construct validity by experts, in other words the instrument tested has not yet known the validity level; 2 . Based on the results of the trial, the instrument has a level of difficulty: $68 \%$ easy, $12 \%$ moderate, $16 \%$ difficult, and $4 \%$ very difficult. The spread of this difficulty level has not been set; 3 . The trial was conducted on 5 respondents with an age range: 4 years 5 months to 5 years 10 months, or the age range was 1 year 5 months $=17$ months; 4 . The five classes range of respondents is Kindergartengrade $\mathrm{A}$ to Kindergarten -grade $\mathrm{B} ; 5$. Instruments that have been tested can be used to select the readiness of children to enter elementary school from the cognitive aspect - Piaget; 6. Cognitive abilities tested using instruments are the ability to think symbolically and intuitively, as well as assimilation and accommodation; 7. The instrument has an easy level of difficulty in the intuitive aspects. But this could be due to the child's primitive thinking ability which is indeed good and quite developed following the progress of the times; 8 . Instruments have a level of difficulty - very difficult in aspects of accommodation. Only $4 \%$ of the respondent's ability to answer this aspect, but it can indeed be because the problem format is too high or difficult for children around 5 years old.

\section{CONCLUSION}

The main key to intellectual development is the organizational process and adaptation to the schemes that children get. Based on Piaget's theory, instruments were developed to test the readiness of children to enter elementary school. The basic concept of the instrument uses variables or aspects of symbolic, intuitive thinking, assimilation, and accommodation because Piaget's children aged 2-7 years are in the preoperational phase.

Instruments made and tested have been effective in assessing children's readiness to enter elementary school. The instrument was able to produce the final score of 5 respondents with an average range of $74.3 \%$ to $85 \%$. The average respondent's ability to answer is $79.76 \%$. These results mean that students are quite cognitively prepared to enter elementary school. Based on existing data, the most understood aspect of respondents is the aspect of intuitive thinking. Conversely, the most difficult aspect for respondents to understand is the aspect of accommodation thinking. Based on the average score of each respondent and the average score of at least $60 \%$, all respondents passed the primary school readiness 
test. It is hoped that subsequent research will develop children's readiness at other stages of development.

\section{REFERENCES}

Adler, M. G. \& Fagley, N. S. (2005). Appreciation: Individual Differences in Finding Value and Meaning as a Unique Predictor of Subjective Well-Being. Journal of Personality, 73(1), 80-114.

Bada, S. O. (2015). Constructivism Learning Theory: A Paradigm for Teaching and Learning. Journal of Research \& Method in Education. 5(6), 66-70.

Bashrin, S. D. (2015). Piaget's Pre-operational Stage in Children: A Comparative Study. Bangladesh: Department of English and Humanities, BRAC University.

Bormanaki, H. B. \& Khoshhal, Y. (2017). The Role of Equilibration in Piaget's Theory of Cognitive Development and Its Implication for Receptive Skills: A Theoretical Study. Journal of Language Teaching and Research, 8(5), 996-1005.

Devi, L. (1998). Child development an introduction. New Delhi: Anmol Publications.

Eccles, J. S. (1999). The Development of Children Ages 6 to 14. The Future of Children when school is out, 9(2), 30-44.

Feldman, D. H. (2004). Piaget's stages: The unfinished symphony of cognitive development. New Ideas in Psychology, 22(3), 175-231.

Institute of Medicine (IOM) and National Research Council (NRC). (2015). Transforming the workforce for children birth through age 8: A unifying foundation. Washington, DC: The National Academies Press.

Joubish, M. F., \& Khurram, M. A. (2011). Cognitive Development in Jean Piaget's Work and its Implications for Teachers. World Applied Sciences Journal, 12(8), 1260-1265.

Lefudin. (2017). Belajar dan Pembelajaran. Yogyakarta: Deepublish.

Lumen Learning. Piaget's Theory of Cognitive Development. [online]. Retrieved from https://courses. lumenlearning.com/teachereducation $\times 92 \times 1 /$ chapter/piagets-theory-of-cognitive-development/

Madaschi, V., Mecca, T. P., Macedo, E. C., \& Paula, C. S. (2016). Bayley-III scales of infant and toddler development: transcultural adaptation and psychometric properties. Paidéia (Ribeirão Preto), 26(64), 189-197.

Marwaha, S., Goswami, M., \& Vashist, B. (2017). Prevalence of Principles of Piaget's Theory Among 4-7-year-old Children and their Correlation with IQ. Journal of clinical and diagnostic research, 11(8), ZC111.

Marocco, D., Cangelosi, A., Fischer, K., \& Belpaeme, T. (2010). Grounding Action Words in the Sensorimotor Interaction with the World: Experiments with a Simulated iCub Humanoid Robot. Front Neurorobotics, 4(7), 1-9.

McLeod, S. A. (2018). Concrete operational stage. Retrieved from https://www.simplypsychology. org/concrete-operational.html

Molai, T. N. (2016). Factors Affecting Language Development of Children. International Academic Journal of Social Sciences, 3(1), 45-56.

Moshman, D. (1998). Cognitive Development beyond Childhood. New York: Wiley.

Parke, R., \& Gauvain, M. (2009). Child Psychology A Contemporary Viewpoint. New York: Mc Graw Hill.

Pem, D. (2015). Factors Affecting Early Childhood Growth and Development: Golden 1000 Days. Adv Practice Nurs, 1(101), 2573-0347.

Rintoul, B. (1998). Factors in Child Development. North Carolina: Research Triangle Institute Center for Research in Education.

Santrock, J. (2007). Perkembangan Anak. Jakarta: Erlangga.

Simatwa, E. D. G. (2010). Piaget's theory of intellectual development and its implication for instructional management at presecondary school level. Educational Research and Reviews, 5(7), 366-371.

Spies, T. G., Lyons, C., Huerta, M., Garza, T., \& Reding, C. (2017). Beyond Professional Development: Factors Influencing Early Childhood Educators' Beliefs and Practices Working with Dual Language Learners. Catesol Journal, 29(1), 23-50.

Unsworth, S. \& Marinis, T. (2011). The impact of internal and external factors in child second language acquisition. Linguistic Approaches to Bilingualism. doi: 10.1075/lab.1.3.00int

Wood, K. C., Smith, H., \& Grossniklaus, D. (2001). Piaget's Stages of Cognitive Development. In M. Orey (Ed.), Emerging perspectives on learning, teaching, and technology. 